Rhode Island College

Digital Commons @ RIC

\title{
The Impact of Preoperative Warming of Ambulatory Surgery Patients on the Prevention of Postoperative Hyposthermia
}

\author{
Mary Jean Croft \\ Rhode Island College
}

Follow this and additional works at: https://digitalcommons.ric.edu/etd

\section{Recommended Citation}

Croft, Mary Jean, "The Impact of Preoperative Warming of Ambulatory Surgery Patients on the Prevention of Postoperative Hyposthermia" (2010). Master's Theses, Dissertations, Graduate Research and Major Papers Overview. 76.

https://digitalcommons.ric.edu/etd/76

This Major Paper is brought to you for free and open access by the Master's Theses, Dissertations, Graduate Research and Major Papers at Digital Commons @ RIC. It has been accepted for inclusion in Master's Theses, Dissertations, Graduate Research and Major Papers Overview by an authorized administrator of Digital Commons @ RIC. For more information, please contact digitalcommons@ric.edu. 


\section{Approval Sheet}

THE IMPACT OF PREOPERATIVE WARMING OF AMBULATORY SURGERY PATIENTS ON THE

\section{PREVENTION OF POSTOPERATIVE HYPOTHERMIA}

\section{A Major Paper Presented}

By

Mary Jean Croft, BSN, RN, CNOR

Approved:

Committee Chairperson

Committee Members
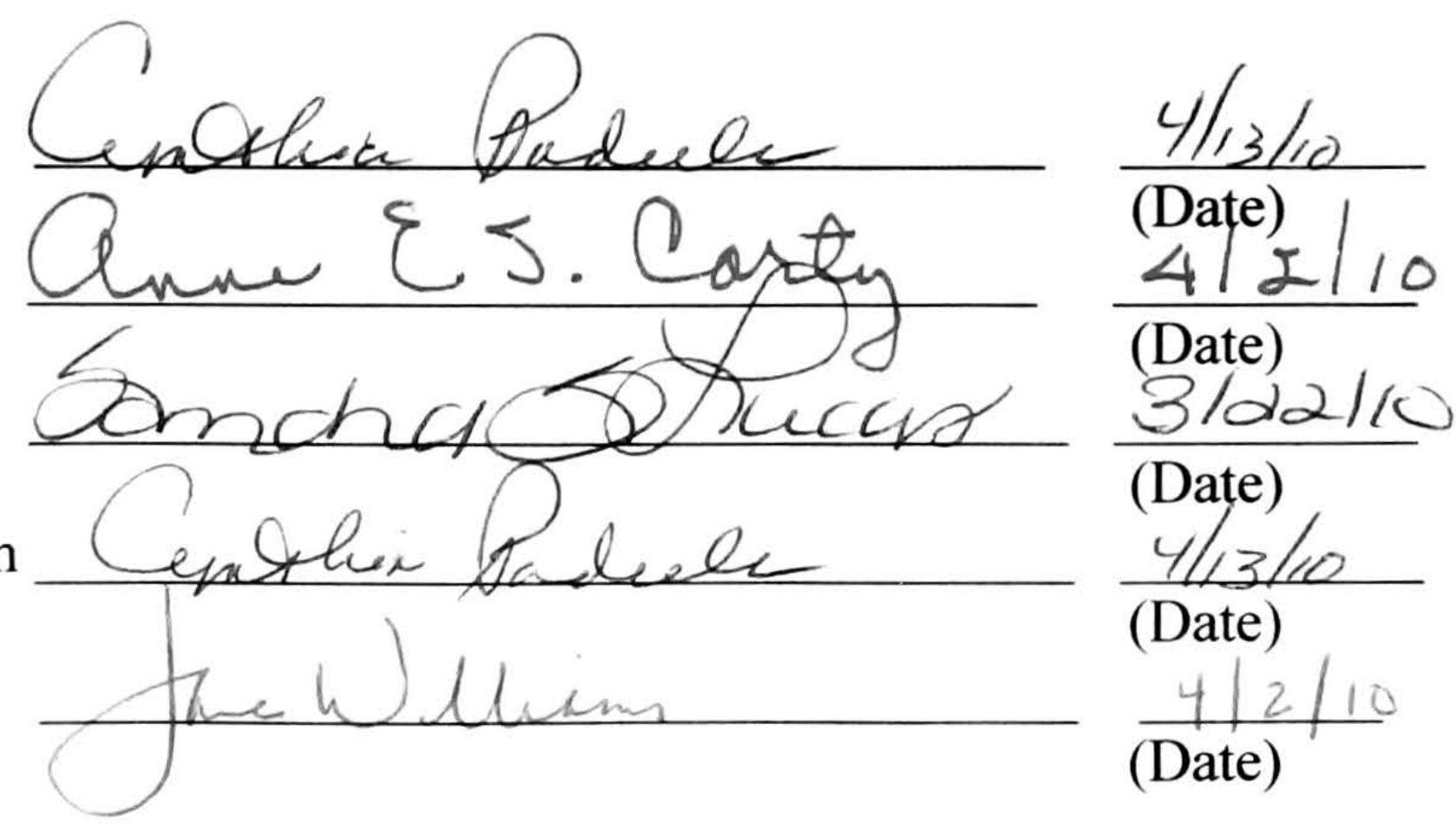
THE IMPACT OF PREOPERATIVE WARMING OF AMBULATORY SURGERY

PATIENTS ON THE

PREVENTION OF POSTOPERATIVE HYPOTHERMIA

by

Mary Jean Croft, BSN, RN, CNOR

A Major Paper Submitted in Partial Fulfillment

of the Requirements for the Degree of

Master of Science in Nursing,

in

The School of Nursing

Rhode Island College

2010 
Table of Contents.

Abstract.

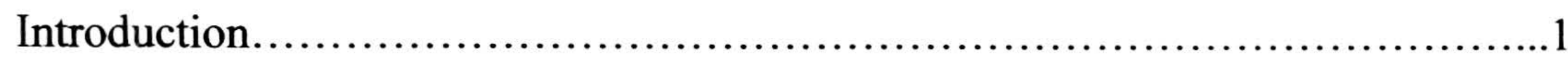

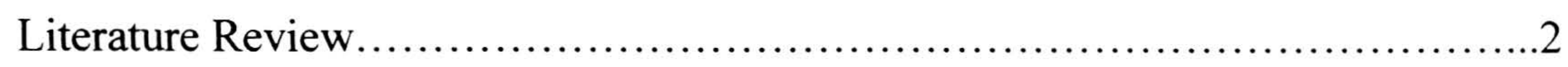

Theoretical Framework ...............................................................

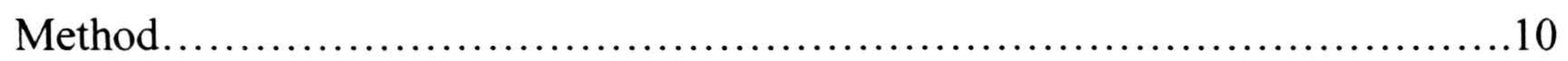

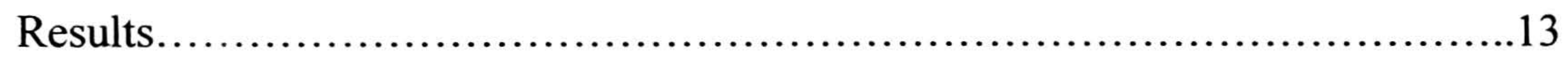

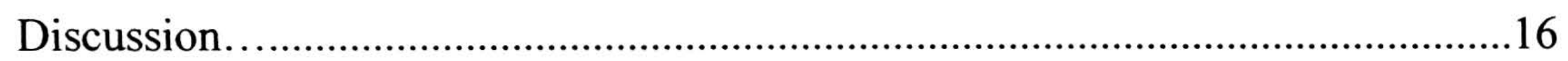

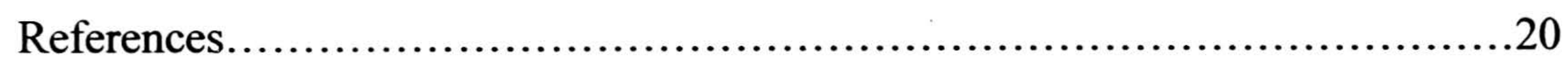

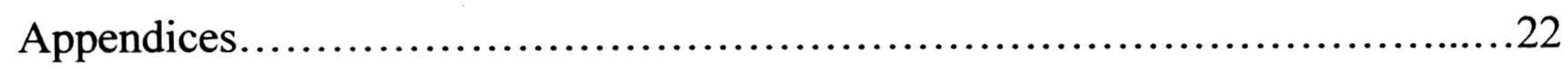

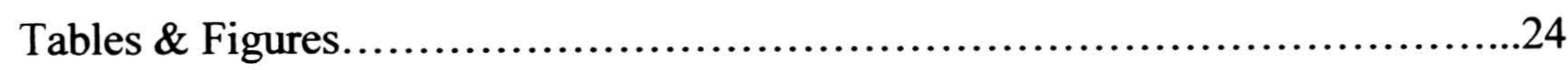


This major paper was submitted for publication consideration to the AORN Journal. The paper formatting and guidelines presented conform to the publication requirements of AORN journal. 


\section{ABSTRACT}

Postoperative hypothermia is a continuing problem in surgical patients. Preoperative warming has been shown to benefit patients undergoing major surgical procedures but studies are lacking in patients in the ambulatory setting.

Objective: The purpose of this study was to explore the effect of warming ambulatory surgical patients preoperatively prior to anesthesia induction and surgery on maintenance of core body temperature, prevention of hypothermia in PACU, and patient comfort.

Method: A convenience sample of 96 adult patients undergoing ambulatory surgery was provided standard care (cotton bath blankets) $(n=47)$ or pre-warming (Bair Paws ${ }^{\circledR}$ Flex warming gown) (n=49). All patients received forced air warming intraoperatively.

Results: The mean pre-warming time was 58.6 minutes. The intervention group mean temperatures were significantly improved (intervention mean 97.304 pre vs. 98.044 post; $p=0.002$ vs. control mean 97.54 pre vs. 97.87 post; $p=0.063)$ upon discharge from the preoperative holding area and prior to transport to the OR surgical suite. There was a 0.13 degree $\mathrm{F}$ increase in mean core temperature to PACU in the pre-warmed group as compared to control (intervention means 97.66 vs. control mean $97.53 ; 95 \% \mathrm{CI}$ ). The control group had a mean temperature decrease of $0.01^{\circ} \mathrm{F}$ from preop temperature to PACU while the intervention groups' mean temperatures increased by $0.19^{\circ} \mathrm{F}$. Seven patients in the control group arrived to PACU complaining of cold and one shivering, compared to one patient in the intervention group.

Conclusions: Preoperative warming utilizing the Bair Paws ${ }^{\mathbb{R}}$ flex warming gowns increased patients' core temperatures on arrival to PACU and lessened the number of patients arriving to PACU complaining of cold. 
Keywords: hypothermia, ambulatory surgery, warming devices, pre-warming, normothermia. 
THE IMPACT OF PREOPERATIVE WARMING OF AMBULATORY SURGERY

PATIENTS ON THE

\section{PREVENTION OF POSTOPERATIVE HYPOTHERMIA}

Hypothermia is a serious problem that affects surgical patients in both the ambulatory care setting as well as the main operating room (OR). It is defined as core body temperature lower than $96.8^{\circ} \mathrm{F}\left(36^{\circ} \mathrm{C}\right) .^{1}$ Hypothermia causes serious post op sequelae such as cardiac ischemia, increased oxygen demands from shivering, infection, pressure ulcers, difficult pain management, and decreased thermal comfort, resulting in low patient satisfaction and increased post anesthesia care unit (PACU) time. ${ }^{2}$

Patients complain of cold in the pre operative holding areas, the operating rooms, and the post anesthesia care units. Patients routinely awaken shivering from anesthesia in the operating room (OR) and PACU. Post anesthetic shivering ịs spontaneous, involuntary, and unpredictable muscular activity affecting up to $65 \%$ of patients after general anesthesia and $33 \%$ of patients after regional anesthesia. ${ }^{3}$ When muscle tone increases to more than a critical level, shivering begins, with synchronous contractions of small groups of opposing motor units. The cause of shivering is assumed to be a classic thermoregulatory response against core or skin hypothermia caused by perioperative heat loss. ${ }^{3}$

Bock et al. ${ }^{4}$ pioneered a study focused on discovering whether forced warm air blankets pre-induction and intraoperatively versus warmed bath blankets would improve maintenance of core body temperature during surgery. Twenty patients undergoing general anesthesia and open laparotomy were warmed for 30 minutes pre-induction of anesthesia and actively warmed intraoperatively. The core temperature in the pre- 
warmed group was significantly higher than the control group. A marked difference between forced warm air blankets and warmed bath blankets intraoperatively was demonstrated, but a drop in core temperature still occurred post induction. ${ }^{4}$ Recommendations for further study have indicated more research is needed, particularly related to pre-warming. Pre-warming patients in the holding area before surgery could be beneficial, in addition to warming intraoperatively, in maintaining core body temperature upon admittance to PACU. Pre-warming patients could significantly lower post op sequelae, decrease PACU recovery time, improve patient satisfaction and decrease costs from postoperative complications due to hypothermia.

Evidence is lacking in comparing long procedures with short procedures and in comparing a wider scope of diverse surgical procedures. Most of the procedures studied involved patients undergoing major laparotomies, total joint, replacements and cardiac surgery. Evidence has supported the contention that ambulatory patients and main operating room surgical patients are subjected to the same environmental stressors, including exposure to cold ambient temperature in preoperative and surgical suites, general anesthesia, monitored anesthesia care, varied surgical times, exposed body surfaces and cavities, cold prep and IV solutions. ${ }^{1}$ Little research has been conducted on surgical patients in the ambulatory setting with surgical times of one hour or less.

\section{LITERATURE REVIEW}

A literature review was conducted covering publications from 1995-2009 using the Cumulative Index to Nursing and Allied Health Literature (CINAHL) database and PubMed database. Key words used in the literature search were: hypothermia, 
normothermia, surgical patients, preoperative warming, intraoperative warming, postoperative warming, forced air warming, and postoperative hypothermia prevention. These search key words were also used with modifiers such as ambulatory surgical patients and short-stay surgery, and post operative shivering. The literature reviewed was accepted if it was in English and addressed the effects of forced air warming during surgery or preoperatively in comparison to other methods of warming.

A common theme in the literature was that postoperative hypothermia is a continuing problem in surgical patients. Most of the research conducted has involved patients undergoing major surgical procedures with surgical durations of two hours or more. Little research has been conducted on surgical patients in the ambulatory setting with surgical times of one hour or less.

\section{Intraoperative warming research}

Increased postoperative oxygen demands occur in patients experiencing postoperative shivering. In a randomized control trial (RCT) of 29 surgical patients above the age of 60 , having planned vascular, thoracic or abdominal surgery, incidences of shivering were markedly less, $0 / 15$ in the intervention group compared to $4 / 14$ in the control group, one hour postoperatively. Thermal comfort scores were measured on a 0-10 Likert scale with 10 being extremely warm and 0 extremely cold; most rated comfort at 5 in the intervention group and 3 in the control group. ${ }^{5}$

Significant increases in core body temperature were found in one RCT of 300 surgical patients undergoing total knee replacement with American Society of Anesthesiologists

(ASA) (2009) Class ratings of I or II (ASA Class I are normal healthy patients and ASA 
Class II are patients with a mild systemic disease). This study used forced air warming as compared to resistive heating methods or cotton bath blankets. ${ }^{6}$ Most common in the findings was that forced air warming intraoperatively was superior to other methods of warming such as resistive heating (warm water circulating mattresses or thermal blankets) or warmed cotton bath blankets. The sample and the parameters for measurement were clearly defined. The results showed that the warmed group experienced significantly higher core body temperatures of $0.577^{\circ} \mathrm{C}(95 \% \mathrm{CI}, 0.427$ $0.726 ; \mathrm{p}<0.001)$ and $0.510^{\circ} \mathrm{C}(95 \% \mathrm{CI}, 0.349-0.672 ; \mathrm{p}<0.001)$ than the resistive heating group or the two cotton blanket groups, ${ }^{6}$ after adjusting for age, sex, and patients' induction room temperature.

Matsuzaki et al. ${ }^{7}$ conducted an experimental cross-sectional study of 24 patients undergoing elective laparoscopic cholecsytectomies in the open leg position who were ASA class I or II and age 20-80 years. They found that resistive heating methods such as warm water circulating mattresses or heated pads placed under the patient were not significantly different than forced air warming (circulating water mattress, $36.2 \mathrm{C}$; forced air, 36.8 C; resistive heating, $36.7 \mathrm{C}$ ) in preventing postoperative hypothermia.

Findings are relevant in that results showed that resistive heating and forced air warming were of significant value in maintaining core body temperature to the PACU. ${ }^{7}$ It is important to note that the significant difference between these two studies is the sample size. Siew-Fong's ${ }^{6}$ sample size $(n=300)$ was significantly larger than Matsuzaki's ${ }^{7}(n$ $=24$ ) and may have contributed of why there was such a significant result in forced air 
warming being of greater value in that study than in the Matsuzaki study. A weakness of both studies was that neither gave any indication that further research was needed.

Scott and Buckland ${ }^{8}$ completed a systematic review of intraoperative warming to prevent postoperative complications. They focused on studies that measured the effects of warming therapy during surgery. Most of the studies reviewed compared warming of patients intraoperatively; a few studies conducted preoperative warming. The prewarming studies focused on infection rates and therefore were not included in this literature review. The authors reviewed 26 RCTs totaling 2070 patients; data analysis was carried out using Rev Man Software ${ }^{\circledR}$. The data was pooled and examined for any similarities that were of clinical importance and significance to practice. The reviewers were particularly interested in answering the question: "Does prevention of hypothermia during surgery prevent postoperative complications and improve patient outcomes?" All the studies reviewed compared a standard measure of care to at least one method of preventing hypothermia. Forced air warming was the method most used. The majority of the studies showed a marked difference in core body temperature between the usual standard of care and the institution of a warming method. Of major importance is the conclusion that the reviewers no longer considered it ethical to conduct clinical trials in patients undergoing major surgery and to allow subjects to become hypothermic, considering the scope of the evidence in support of intraoperative warming. Despite this, however, they concluded the effect of preoperative warming (pre-induction of anesthesia) requires more research. ${ }^{8}$ 


\section{Preoperative warming research}

Bock et al. ${ }^{4}$ titled their study "Effects of pre-induction and intraoperative warming during major laparotomy". This study is reviewed extensively because of its significance to the reported study. Bock et al. ${ }^{4}$ appear to have pioneered pre-warming research early in 1998, but much of the subsequent research from that point remained focused on intraoperative warming. The authors investigated warming patients for 30 minutes before induction of anesthesia combined with intraoperative warming with forced air to prevent hypothermia during major abdominal surgery. This problem has significance for perioperative nursing as it is a common problem in the daily work and builds a persuasive argument to provide surgical patients with warming as a standard of care. The variables of interest included pre-induction and intraoperative warming and the target population included patients having major laparotomy. This RCT assigned subjects to either the control group or the pre-warming group; however, the method of randomization was not reported in the article. The control group received conventional treatment consisting of fluid warming devices, circulating water mattresses, and cotton blankets. Extraneous variables such as ambient OR room temperatures, surgical procedures, length of surgery and patient demographics that affect heat loss were also precisely identified as to their effects on core body temperature. The data analysis was identified primarily as ANOVA. Statistical data were provided and showed significant improvement in core body temperatures. Changes in core temperatures were less in the pre-warmed group as compared to the control $\left(0.5^{\circ} \mathrm{C}\right.$ [pre-warmed group] vs. $1.5^{\circ} \mathrm{C}$ [control group]; $\left.\mathrm{p} \leq 0.01\right) .{ }^{4}$ Platelet level, core body temperature, and length of stay in PACU were reported as 
preoperative, intraoperative, and postoperative values. The major finding was that maintenance of normothermia helped to reduce length of PACU stay with a $24 \%$ reduction in costs. A significant reduction in perioperative blood loss was also reported (one patient in pre-warmed group received two units of packed red blood cells compared to six patients in the control group). ${ }^{4}$ Recommendations for further study were not mentioned in the conclusion. Further study in patients having other surgeries and with shorter operative times, such as ambulatory surgery, is needed.

Bitner, Hilde, Hall and Duvendack ${ }^{1}$ utilized a team approach and performance improvement process to implement an intervention to prevent unplanned postoperative hypothermia. The researchers hypothesized that preoperative forced air warming in addition to intraoperative forced air warming could improve this patient population's post operative outcomes. The purpose of the project was to compare the post operative temperatures of the pre-warmed group to the non pre-warmed group. The control group was treated according to the institution's current practice (no pre-warming), and compared to the treatment group that had forced warm air upper body blankets applied preoperatively. Results graphically depicted improvements in postoperative core temperatures in the groups that received preoperative forced air warming. The graphs showed less of a downward trend in core body temperature $\left(-5^{\circ} \mathrm{F}-+2^{\circ} \mathrm{F}\right.$ [no prewarming] vs. $-1^{\circ} \mathrm{F}-+2^{\circ} \mathrm{F}$ [pre-warmed]). ${ }^{1}$

Andrzejowski, Hoyle, Eapen and Turnbull ${ }^{9}$ conducted a RCT involving pre-warming 31 patients undergoing spinal surgery utilizing the Bair Paws ${ }^{\circledR}$ Flex Gown system. Preoperative core temperature was measured with a temporal artery scanner (Exergen ${ }^{\circledR}$ 
Corporation, MA.). This study group received 60 minutes of pre-warming. Variables that were recorded included ambient room temperatures, patient age, Basal Metabolic Index (BMI), gender, duration of surgery, core temperatures pre-intervention and at induction. The intervention was the application and use of the Bair Paws ${ }^{\circledR}$ flex warming gown preoperatively. The findings showed that the preoperative warming resulted in smaller decreases in core temperatures intraoperatively and less inadvertent perioperative hypothermia. A larger proportion of patients remained normothermic in the pre-warmed group $(68 \%)$ than in the control group $(43 \%)(p<0.05) .{ }^{9}$ In summary, research has shown the significant positive effects of pre-warming patients for major surgical procedures. There is a plethora of information supporting forced warm air intraoperative warming. More research is essential to examine the effects of pre-warming patients in relation to ambulatory surgery.

Medical and nursing staff members need to be more diligent in maintaining normothermia related to the knowledge that the reduction of core temperature within the first hour of anesthesia induction is a result of redistribution; internal heat flow from the warmer core to the colder periphery. ${ }^{3}$ Patients who are having minor surgery and outpatient ambulatory surgery appear to be at great risk for hypothermia due to this exposure window. ${ }^{3}$ It is on this knowledge that the following question is based: If patients were pre-warmed, would there be a significant effect on reducing post-induction drop of core body temperature and increasing the benefit of intraoperative warming to maintain core body temperature to PACU? 


\section{THEORETICAL FRAMEWORK}

\section{The Perioperative Patient Focused Model}

The theoretical framework applied to this study is the Perioperative Patient Focused $\operatorname{Model}^{10}$ (Appendix A). The patient and his/her family are at the core of the model, surrounded by concentric circles that symbolize the perioperative nursing process. The perioperative nurse's most important focus is the patient despite the type of practice setting, geographic location or nature of the patient population. This model is appropriate for research, as evidence will potentially improve outcomes for the patient, at the center of care in the operating room environment. The dimensions or domains of clinical perioperative nursing include safety, physiological responses to surgery, behavioral responses to surgery and the health system with outcomes that are financial, operational, and institutional initiatives. ${ }^{11}$ The model is circular and within each domain the concentric circles expand beyond the patient and family representing the perioperative nursing domains and elements. ${ }^{12}$ Each dimension or domain has problems or diagnoses that are characteristic of surgical patients identified. Most common to the surgical patient are the physiologic responses to unplanned hypothermia, such as increased postoperative shivering resulting in increased oxygen demands, cardiac ischemia, pain, increased length of stay, increased incidence of pressure ulcers and infections. Outcomes are identified and defined, Nursing interventions have been delineated to achieve each outcome and outcome indicators have been specified for evaluation. ${ }^{10}$ The outcomes focus of this model is particularly important, as all nursing theories should represent all components of the nursing process, including outcomes. The AORN's model represents outcome- 
driven nursing practice by positioning the outcome element in the model next to the patient care domains, preceding individual patient assessment and nursing diagnosis. The perioperative nurse has a unique knowledge base from which to acquire a set of outcomes that applies to all patients who receive care in the perioperative setting. From these outcomes, or in addition to them, the perioperative nurse selects nursing diagnoses based on assessment of the individual patient. Evidence-based practice can then be instituted based on the fact that these outcomes can be measured and evaluated for relevance to patient care in the operating room, thus expanding the database for perioperative care.

\section{METHODS}

The research question was: What is the effect of pre-warming ambulatory surgical patients with forced air blankets preoperatively, in comparison to warmed bath blankets, in maintaining core body temperatures to PACU and on patient comfort?

Permission to perform the study was obtained from immediate supervisors and the Director of Surgical Services at the institution. The Institutional Review Boards of the Hospital and the College both approved the study and waived consent.

A nonequivalent control group before-after design was implemented. Due to the difficulty of ethically randomizing patients in a surgical holding unit setting, a quasiexperimental design was chosen. Two groups of surgical patients were studied for core body temperature with routine standard care vs. intervention: patients receiving two warmed cotton blankets preoperatively (standard) and forced warm air intraoperatively; and patients receiving forced warm air preoperatively, utilizing the Bair Paws ${ }^{\circledR}$ Flex warming gowns, (intervention) as well as intraoperatively. The independent variable was 
method of warming; outcome variables included core body temperature to PACU and patient satisfaction to PACU. Extraneous variables identified included ambient room temperatures, length of surgery, type of surgery, age, height, weight, sex and BMI.

\section{Sample}

A convenience sample of ambulatory surgical patients was obtained. Surgical patients were assigned to groups based on the week during which surgery was scheduled. One week was assigned to the data collection for each group. During week one of data collection, patients received standard care: two warmed cotton blankets preoperatively and forced warm air intraoperatively; during week two, patients received forced warm air preoperatively (utilizing the Bair Paws ${ }^{\circledR}$ Flex warming gowns) and intraoperatively. Data was collected exclusively on ambulatory surgical patients, and all ambulatory surgical patients having anesthesia (general, monitored anesthesia care or regional) were included in the study. The pre-warmed group received the intervention utilizing the Bair Paws ${ }^{\circledR}$ flex gowns instead of the usual patient cloth gown. Patients were allowed to control the temperature of their gowns with their own self regulator on the small portable heaters in the pre operative holding unit. This gave the patients a sense of control over their comfort.

\section{Procedure}

Data was collected utilizing the data collection instrument adopted from the American Society of Peri-Anesthesia Nurses (ASPAN) Clinical Guidelines for the Prevention of Unplanned Perioperative Hypothermia. The instrument, as developed by ASPAN, was modified slightly to reflect the ambulatory surgery setting. The separate 
sections were color-coded to indicate the different phases of data collection. The preoperative area was color coded purple, OR blue and PACU pink. Additional areas for data collection pertinent to this study were added (Appendix B), and demographic information was recorded on the tool.

Data were collected by the nurses caring for the patients. The staff actively participated in the study to facilitate a broad sense of active involvement in the process. Before the start of the study, an in-service was provided by the investigator to nursing staff and included the study purpose, use of the data collection tool, a brief overview of procedures for each of the groups, and basic information related to use of the Bair Paws ${ }^{\circledR}$ flex gown. The sales representative trained the staff in the specific use of the Bair Paws ${ }^{\circledR}$ flex gown, which had not been previously used in the facility. The researcher was available during data collection to answer questions either in person or by cellular phone and to assure that data was collected appropriately and completely. The researcher regularly collected data with nurses on individual patients to ensure accuracy. Data recorded between the researcher and the nurses were consistently highly comparable. The researcher reviewed data collection sheets for completeness and missing data was obtained from the patients'electronic medical record whenever possible.

Ambient room temperature and patient core temperature were monitored throughout the study. All thermometers were evaluated prior to the start of the study by the Clinical Engineering department in the hospital, to best ensure proper functioning of the units and calibration according to manufacturer's guidelines. Ambient room temperatures were monitored via digital thermometers that displayed room temperature. These digital 
thermometers were added in the preoperative and PACU suites by Clinical Engineering since they were already in place in the ORs. Lock boxes were installed on all thermostats to prevent the possibility that the room temperature settings could be changed. Patient temperature and room temperature were recorded on the data collection instrument upon patients' admittance to the preoperative holding area, upon leaving the preoperative holding unit, upon arrival to the surgical suite, intraoperatively, and upon arrival to the PACU. Body temperature was measured in the preoperative and postoperative areas utilizing the Exergen ${ }^{\circledR}$ Temporal Scanner according to the manufacturers' guidelines. Temperature was monitored in the operating room utilizing the Sharn Temp Alert II ${ }^{\circledR}$ skin temperature sensor. The researcher regularly rounded on the units to ensure that devices were in working order and to be available to answer questions from the staff. RESULTS

The data was analyzed utilizing the PASW ${ }^{\circledR}$ Statistics GradPack 17.0. The sample consisted of 96 subjects, 47 in the control group and 49 in the intervention group. The control group included 26 females and 21 males, as compared to 28 females and 18 males in the intervention group (data was missing on 3 subjects). There was no significant difference in patient characteristics; patients in both groups were, on average, overweight and their ages were varied (Table 1). The mean time of surgery in the control group was 46.61 minutes (range 7-180 minutes) with a mean time in the intervention group of 34 minutes (range 3-116 minutes). The intervention group's mean surgery time was shorter (Table 2). The majority of the patients in both groups received general anesthesia: $74.5 \%$ in the control group and $73.5 \%$ in the intervention group. Procedures for the two groups 
were varied and provided a wide range of diversity to the sample (Figures $1 \& 2$ ). A small difference in the range of room temperatures occurred between the groups: preop $2.9^{\circ} \mathrm{F}$ (control) vs. $3.0^{\circ} \mathrm{F}$ (intervention); PACU $2.2^{\circ} \mathrm{F}$ (control) vs. $4.6^{\circ} \mathrm{F}$ (intervention). A greater difference in the range of room temperatures occurred in the OR theatre, $5.3^{\circ} \mathrm{F}$ (control) and $5.8^{\circ} \mathrm{F}$ (intervention) (Table 3).

Patients in the intervention group were warmed preoperatively with the Bair Paws ${ }^{\circledR}$ gown a mean time of 58.6 minutes range ( 15 - 135 minutes). The intervention group mean temperatures were significantly improved (intervention mean 97.304 pre vs. 98.044 post; $\mathrm{p}=0.002$ vs. control mean 97.54 pre vs. 97.87 post; $\mathrm{p}=0.063$ ) upon discharge from the preoperative holding area and transport to the OR surgical suite (Table 4). The PASW $^{\circledR}$ Statistics Grad Pack 17.0 identified an overall small increase in core body temperature of 0.13 degrees ( 97.66 intervention vs. 97.53 control; $95 \% \mathrm{CI}$ ) upon arrival to PACU in the intervention group. Because the mean temperatures by group appeared different, a $t$-test was performed to examine for significance (Table 5). The control group had a mean temperature decrease of $0.01^{\circ} \mathrm{F}$ from the preoperative temperature to PACU while the intervention group had a mean temperature increase of $0.19^{\circ} \mathrm{F}$ of core body temperature to PACU. These results were not statistically significant but are clinically significant to the care we provide to surgical patients.

Surprisingly, patients in both groups had a drop in core body temperature post induction of anesthesia. A post induction drop in core body temperature continues to occur even after patients are pre-warmed. ${ }^{9}$ What was surprising in this study was that the control group had an intraoperative mean temperature of $97.371^{\circ} \mathrm{F}$. as compared to 
the intervention group intraoperative mean core temperature of $96.762^{\circ} \mathrm{F}$. The intervention groups' mean core temperature was $0.609^{\circ} \mathrm{F}$ lower than the control group. The significant temperature difference between the OR suite and the preoperative holding unit $\left(5.3^{\circ} \mathrm{F}\right.$ [control] and $5.8^{\circ} \mathrm{F}$ [intervention] (Table 3$)$ and the utilization of the Sharn ${ }^{\circledR}$ temp strips vs. the Exergen ${ }^{\circledR}$ temporal scanner may have influenced the difference in temperatures between these two groups (Table 6).

Overall patients' complaints of pain, cold and shivering were noteworthy in the intervention group. Of the 47 patients in the control group, seven arrived to PACU complaining of cold and one arrived complaining of cold and shivering, compared to the intervention group $(n=49)$ in which only one arrived complaining of cold. In the control group, seven patients arrived to the PACU with a pain score $>7$ out of 10 as compared to the intervention group, with three patients that arrived to the PACU with a pain score $>7$ out of 10 .

Patients in the intervention group were followed up at home with a phone call from a representative of the participating institution and answered an evaluation questionnaire related to the use of the Bair Paws ${ }^{\circledR}$ system. This evaluation questionnaire was not part of the design for this study, but the results are relevant to patient satisfaction and are reported here. The Bair Paws ${ }^{\circledR}$ flex gowns were rated on a 5 point Likert scale, with 5 strongly agree and 1 strongly disagree. The institution's evaluation of the product showed that of the 51 patients who responded to the questionnaire, $86.3 \%$ strongly agreed/agreed that the gown kept them comfortable, $84.3 \%$ strongly agreed/agreed that it was easy to adjust the temperature setting on the gown to a comfortable range, and $78.4 \%$ 
strongly agreed/agreed to preferring the warming gown to the hospital standard cloth gown and bath blankets.

\section{DISCUSSION}

The National Institute for Clinical Excellence (NICE) has defined a temperature difference of $0.2^{\circ} \mathrm{C}$ between an intervention and control group as being of clinical significance in hypothermic patients. ${ }^{13}$ Preoperative temperatures were higher in the intervention group by $0.174^{\circ} \mathrm{F}$, as compared to the control group (98.044 intervention vs. $97.87^{\circ} \mathrm{F}$ control) upon discharge to the $\mathrm{OR}$. Mean patient core temperatures to PACU were $0.13^{\circ} \mathrm{F}$ higher in the intervention group than the control. Significant for this study is the increase in mean core body temperatures in the intervention group to maintaining normothermia to PACU. Patient comfort was increased and clinically relevant to the care perioperative nurses provide to surgical patients.

Limitations of this study included that the patients were allowed to control the temperature of their pre-warming units, which may have impacted the results. Limited demographic data was collected and it was assumed that the patient sample was representative of the institutions' ambulatory surgery patients. The variable amounts of time in the preoperative area, which were secondary to wait times for surgery, fluctuated depending upon the duration of surgery and surgeon availability; therefore, some patients received warming longer than others. Participating subjects underwent a wide variety of procedures during this study which impacted OR wait times. Further research might study similar ambulatory procedures in specified OR rooms. Environmental factors, related to the substantial temperature difference between the preoperative holding area 
and the operating room theatre, may have influenced core body temperature results intraoperatively and to PACU. Intraoperative temperature results may have been skewed related to the different instruments used in the preoperative and PACU areas vs. the OR. An important nursing consideration is that operative nursing temperature-taking must be consistent and comparable in measurement.

Heat loss during surgery is inevitable. Thermal redistribution occurs after induction of anesthesia and accounts for a decrease in core temperature of up to $1.6^{\circ} \mathrm{C}^{3914}$ Precautions must be taken to ensure that this is kept to a minimum. The complications of hypothermia must be minimized and patient comfort and satisfaction are paramount to the care of surgical patients. Intraoperative warming with forced warm air is routine, but inadvertent hypothermia still occurs. Perioperative nurses are at the forefront for implementing preoperative warming techniques prior to the start of surgery to ensure that patients are at optimum temperatures to reduce the incidence of inadvertent perioperative hypothermia. Many initiatives have been recommended including those from the Institute for Healthcare Improvement (IHI), the Surgical Care Improvement Project, the National Quality Forum, the Center for Disease Control and The Joint Commission. These agencies have targeted surgical site infections and have advised facilities to use warmed forced-air blankets preoperatively, during surgery and in PACU to prevent inadvertent hypothermia and decrease the incidence of surgical site infections. AORN, ASPAN, ASA and many other professional organizations have adopted normothermia recommendations into their patient safety initiatives. ${ }^{15}$ A recent quantitative descriptive study evaluated perioperative nurses' knowledge of preventing inadvertent hypothermia. 
Results showed that nurses' definitions were varied and inconsistent. It is imperative that standardized guidelines from NICE, ASPAN or AORN be adopted. ${ }^{16}$ The Clinical Nurse Specialist has the potential to impact policy change across the perioperative experience, rendering consistency in warming methods, temperature-taking and dissemination of standardized clinical guidelines.

This work examined a technological innovation of pre-warming ambulatory patients with a warming gown as compared to standard care with bath blankets. More research should be done to measure the effect of pre-warming ambulatory patients to manage inadvertent perioperative hypothermia during similar procedures in specified OR rooms. Perioperative Clinical Nurse Specialists conducting research are vital for preventing hypothermia and increasing patient comfort and satisfaction. Utilizing the evidence-based practice of pre-warming has the potential to improve postoperative outcomes for patients, increase postoperative comfort and improve patient satisfaction. Further nursing research in this area is needed. 


\section{ACKNOWLEDGEMENTS}

I would like to thank Kent Hospital for allowing me to conduct my major project study in their operating room during their trial of the Bair Paws ${ }^{\circledR}$ flex warming gowns and also Cathy Insana BSN, RN, CNOR, Perioperative Educator at Kent Hospital, for vigilance in following up on data collection sheets when I could not be there. I would also like to thank Cynthia Padula, $\mathrm{PhD}, \mathrm{RN}$ at Rhode Island College for her expertise and guidance during my major project. 


\section{REFERENCES}

1. Bitner J., Hilde K., Hall K., Duvendack T. A team approach to the prevention of unplanned postoperative hypothermia. AORN J. 2007; 85(5): 921-929.

2. Hooper V. Adoption of the ASPAN clinical guideline for the prevention of unplanned preoperative hypothermia. $J$ of Perianesth Nurs. 2006; 21(3): 177-183.

3. Kiekkas P., Poulopoulou M., Papahatzi A., Souleles P. Effects of hypothermia and shivering on standard pacu monitoring of patients. AANA J. 2003; 73(1): 47-55.

4. Bock M., Muller J., Bach A., Bohrer H., Martine E., Motsch J. Effects of preinduction and intraoperative warming during major laparotomy. Br J Anaesth. 1998; 80:159163.

5. Krenzischek D., Frank S., Kelly S. Forced air warming versus routine thermal care and core temperature measurement sites. $J$ Post Anesth Nurs. 1995; 10(2):69-78.

6. Siew-Fong N. A comparative study of three warming interventions to determine the most effect on maintaining perioperative normothermia. Anesth Analg. 2003; 96:171176.

7. Matsuzaki Y., Matsukawa T., Ohki K., Yamamoto Y., Nakamura M., Oshibuchi T. Warming by resistive heating maintains perioperative normothermia as well as forced air heating. Br J Anaesth. 2003; 90(5):689-691

8. Scott E. \& Buckland R. A systematic review of intraoperative warming to prevent postoperative complications. AORN J. 2006; 83(5):1090-1113

9. Andrzejowski J., Hoyle J., Eapen G., Turnbull D. Effect of pre-warming on post induction core temperature and the incidence of inadvertent perioperative hypothermia in patients undergoing general anaesthesia. Br J Anaesth. 2008; 101(5):627-631.

10. Rothrock J., Smith D. Selecting the perioperative patient focused model. AORN J. 2000; 71(5):1030-1037.

11. Kleinbeck S., Dopp A. The perioperative nursing data set-a new language for documenting care. AORN. 2005; 82(1):50-57.

12. Beyea S.C. Perioperative nursing data set: The perioperative nursing vocabulary. $2^{\text {nd }}$ ed. Denver: AORN; 2002. 
13. Clinical Practice Guideline. The management of inadvertent perioperative hypothermia in adults. April, 2008. Available at: http://Retrieved from http://www.nice.org.uk/nicemedia/pdf/CG65Guidance.pdf.

14. Sessler DI. Review: Perioperative heat balance. Anesthesiology. 2000; 92:578-596.

15. Arizant Health Care Inc. U.S. HealthCare Initiatives Turn Focus to Normothermia. February, 2009. Available at: http://Retrieved from http://www.preventhypothermia.org/pdf/us/prevent/602918.pdf. Accessed January 29, 2010 .

16. Hegarty J., Walsh E., Burton A., Murphy S., O'Gorman F., McPolin G. Nurses' knowledge of inadvertent hypothermia. $J$ Adv Periop Care. 2009; 4(1):33-42. 
Appendix A

The Perioperative Patient Focused Model

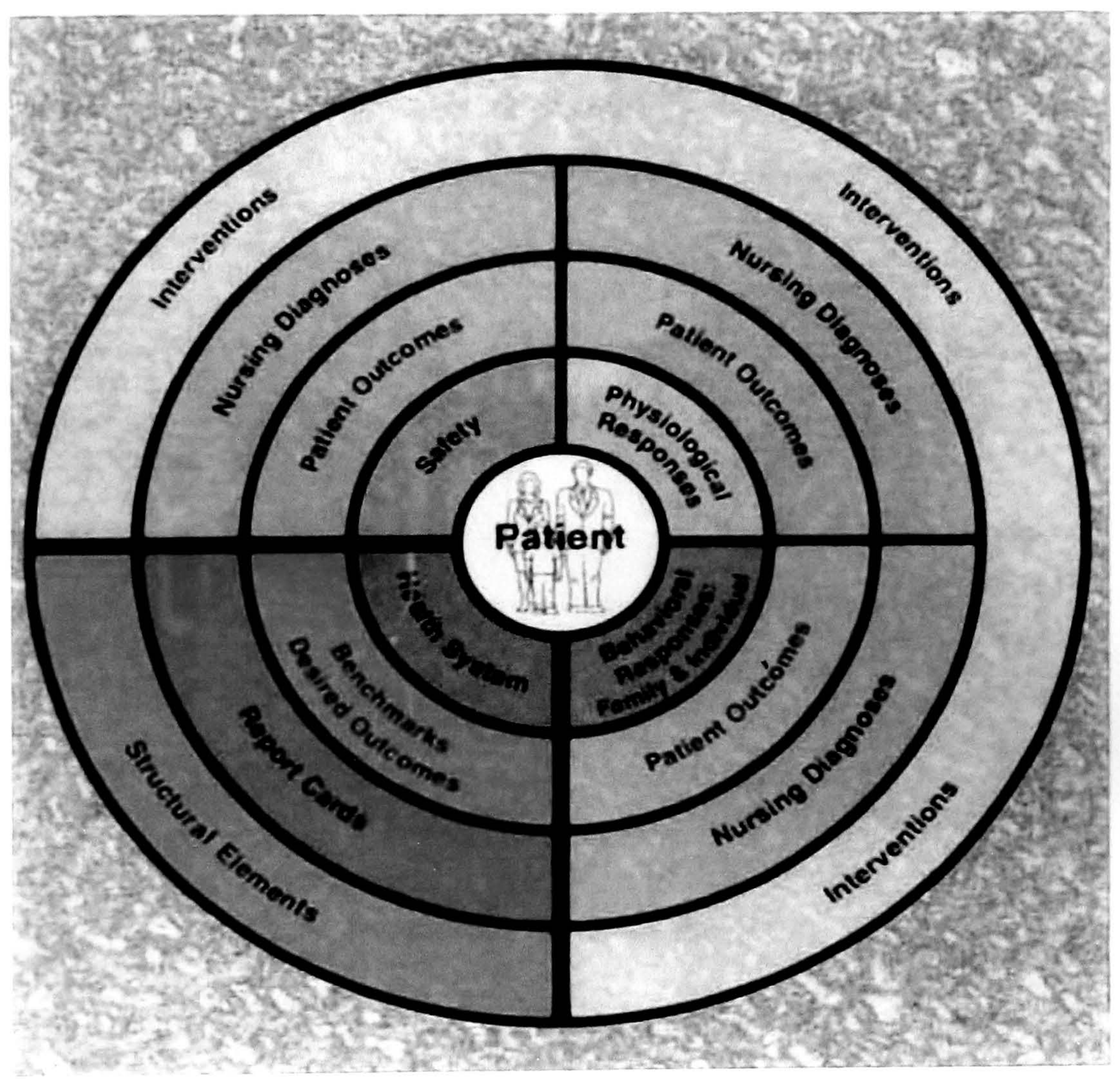




\section{Appendix B}

\section{Data Collection Tool}

Quasi Experimental Study of the Effects of Preoperative warming of Ambulatory Surgical Patients on the maintenance of Core Body Temperature to PACU

\begin{tabular}{|c|c|}
\hline Medical record Number & \begin{tabular}{|lll|l|} 
Anesthesia Type: & Circle one & Surgery: \\
General Mac & Regional & \\
\end{tabular} \\
\hline Patient Demographics & BMI:_ Male__ Female \\
\hline Perioperative Phase & Indicators \\
\hline $\begin{array}{l}\text { Preop Phase } \\
\text { Room Temp: }\end{array}$ & $\begin{array}{l}\text { Admission Temperature } \\
\text { Pain level } \\
\text { Warming method applied: Blankets ___ Bair Paws gown_ } \\
\text { Normothermic before surgery: Yes __ } \\
\text { Thermal Comfort level Assessed: warm___ } \\
\text { Warming Time with Bair Paws gown } \\
\text { Discharge Temperature from Pre op }\end{array}$ \\
\hline \multicolumn{2}{|l|}{ Intraoperative Phase } \\
\hline Room Temp: & $\begin{array}{l}\text { Admission Temperature } \\
\text { Warming method applied: Forced Warm air blanket Yes_ No_ } \\
\text { Bair Paws gown: yes } \\
\text { Normothermic before surgery: yes _ no } \\
\text { IV fluids warmed: yes_no__ } \\
\text { Length of surgery: } \\
\text { Discharge Temperature from OR }\end{array}$ \\
\hline \multicolumn{2}{|l|}{ PACU Phase I } \\
\hline Room Temp: & \begin{tabular}{|l} 
Admission Temperature \\
Pain score upon admission \\
Thermal Comfort level Assessed: warm ___ Cold
\end{tabular} \\
\hline \multicolumn{2}{|l|}{ PACU Phase II } \\
\hline Room Temp: & $\begin{array}{l}\text { Admission Temperature } \\
\text { Pain level } \\
\text { Thermal Comfort level Assessed: warm___Cold }\end{array}$ \\
\hline \multicolumn{2}{|r|}{ Indicator Definitions } \\
\hline $\begin{array}{l}\text { Preoperative Phase } \\
\text { Intraoperative Phase } \\
\text { Pacu }\end{array}$ & \begin{tabular}{|ll}
$\begin{array}{l}\text { Admission temperature } \\
\text { Warming method applied: }\end{array}$ & $\begin{array}{l}\text { First temperature obtained upon } \\
\text { admission to the pre op area }\end{array}$ \\
or Forced Warm Air Blanket or Bair Paws gown. & Two cotton warmed blankets \\
Normothermic & A core temperature greater than \\
& $36^{\circ} \mathrm{C}$ or $98.6^{\circ} \mathrm{F}$.
\end{tabular} \\
\hline
\end{tabular}

Mary Jean Croft RN, BSN, CNOR

Cell: \#\#\#\#\#

Adopted from Data Collection Tool (Hooper, 2006)

Revised July 12, 2009 
Table 1. Characteristics of Sample by Group

\begin{tabular}{|c|c|c|c|c|c|c|c|c|c|c|}
\hline \multicolumn{11}{|c|}{ Characteristics of sample by group: control } \\
\hline & $\mathrm{N}$ & Range & Minimum & Maximum & \multicolumn{2}{|c|}{ Mean } & $\begin{array}{c}\text { Std. } \\
\text { Deviation }\end{array}$ & Variance & \multicolumn{2}{|c|}{ Skewness } \\
\hline & Statistic & Statistic & Statistic & Statistic & Statistic & $\begin{array}{l}\text { Std. } \\
\text { Error }\end{array}$ & Statistic & Statistic & Statistic & Std. Error \\
\hline$\overline{\mathrm{AGE}}$ & $\overline{46}$ & $\overline{76}$ & $\overline{18}$ & $\overline{94}$ & 52.70 & 2.585 & $\overline{17.532}$ & $\overline{307.372}$ & .316 & .350 \\
\hline Weight & 47 & 158.0 & 94.0 & 252.0 & 177.560 & 5.5837 & 38.2802 & 1465.372 & -.224 & .347 \\
\hline BMI & 47 & 30.5 & 13.5 & 44.0 & 28.751 & .8649 & 5.9297 & 35.162 & .253 & .347 \\
\hline \multirow[t]{4}{*}{$\begin{array}{l}\text { Procedure } \\
\text { length }\end{array}$} & 46 & 173 & 7 & 180 & 46.61 & 4.850 & 32.891 & 1081.843 & 1.893 & 350 \\
\hline & & Chara & ristic & is of san & ole by & grou: & : inter & rention & & \\
\hline & $\mathrm{N}$ & Range & Minimum & Maximum & \multicolumn{2}{|c|}{ Mean } & $\begin{array}{c}\text { Std. } \\
\text { Deviation }\end{array}$ & Variance & \multicolumn{2}{|c|}{ Skewness } \\
\hline & Statistic & Statistic & Statistic & Statistic & Statistic & $\begin{array}{l}\text { Std. } \\
\text { Error }\end{array}$ & Statistic & Statistic & Statistic & Std. Error \\
\hline$\overline{\text { AGE }}$ & $\overline{45}$ & $\overline{59}$ & $\overline{26}$ & $\overline{85}$ & 52.29 & 2.037 & 13.663 & 186.665 & .018 & .354 \\
\hline Weight & 47 & 177.0 & 111.0 & 288.0 & 189.511 & 6.2437 & 42.8043 & 1832.212 & .049 & .347 \\
\hline BMI & 47 & 35.4 & 19.0 & 54.4 & 30.464 & 1.0928 & 7.4922 & 56.133 & .812 & .347 \\
\hline $\begin{array}{l}\text { Procedure } \\
\text { length }\end{array}$ & 46 & 113 & 3 & 116 & 34.00 & 4.485 & 30.420 & 925.378 & 1.413 & .350 \\
\hline
\end{tabular}


Table2. Procedure Length in the Control \& Intervention Group

\begin{tabular}{|c|c|c|c|c|c|c|}
\hline \multicolumn{5}{|c|}{ One-Sample Statistics } & & \\
\hline & $\mathrm{N}$ & Mean & $\begin{array}{c}\text { Std. } \\
\text { Deviation }\end{array}$ & $\begin{array}{c}\text { Std. Error } \\
\text { Mean }\end{array}$ & & \\
\hline $\begin{array}{l}\text { Procedure } \\
\text { length } \\
\text { control } \\
\text { Procedure } \\
\text { length } \\
\text { intervention }\end{array}$ & 46 & $\begin{array}{l}46.61 \\
34.00\end{array}$ & $\begin{array}{l}32.891 \\
30.420\end{array}$ & $\begin{array}{l}4.850 \\
4.485\end{array}$ & & \\
\hline \multicolumn{7}{|c|}{ One-Sample Test } \\
\hline & \multicolumn{6}{|c|}{ Test Value $=0$} \\
\hline & \multirow[b]{2}{*}{$t$} & \multirow[b]{2}{*}{ df } & \multirow{2}{*}{$\begin{array}{l}\text { Sig. (2- } \\
\text { tailed) }\end{array}$} & \multirow{2}{*}{$\begin{array}{c}\text { Mean } \\
\text { Difference }\end{array}$} & \multicolumn{2}{|c|}{ Interval of the } \\
\hline & & & & & Lower & Upper \\
\hline $\begin{array}{l}\text { Procedure } \\
\text { length } \\
\text { control } \\
\text { Procedure } \\
\text { length } \\
\text { intervention }\end{array}$ & 7.581 & 45 & .000 & 34.000 & 24.97 & 43.03 \\
\hline
\end{tabular}


Table 3. Room Temperature Pre, Intra and Post-op by Group

\begin{tabular}{|c|c|c|c|c|c|c|c|c|c|c|}
\hline \multicolumn{11}{|c|}{ Room Temperatures Pre, Intra and Post op by group } \\
\hline & $\mathbf{N}$ & Range & Minimum & Maximum & \multicolumn{2}{|c|}{ Mean } & $\begin{array}{c}\text { Std. } \\
\text { Deviation }\end{array}$ & Variance & \multicolumn{2}{|c|}{ Skewness } \\
\hline & Statistic & Statistic & Statistic & Statistic & Statistic & Std. Error & Statistic & Statistic & Statistic & Std. Error \\
\hline $\begin{array}{l}\text { Preop rm } \\
\text { temp control }\end{array}$ & 45 & 2.9 & 68.0 & 70.9 & 69.436 & .1126 & .7556 & .571 & -.300 & .354 \\
\hline $\begin{array}{l}\text { Preop rm } \\
\text { temp } \\
\text { intervention }\end{array}$ & 49 & 3.0 & 67.5 & 70.5 & 69.169 & .1087 & .7611 & .579 & -.209 & .340 \\
\hline $\begin{array}{l}\text { OR rm temp } \\
\text { control }\end{array}$ & 46 & 5.3 & 65.7 & 71.0 & 68.191 & .1928 & 1.3077 & 1.710 & -.086 & .350 \\
\hline $\begin{array}{l}\text { OR rm temp } \\
\text { intervention }\end{array}$ & 49 & 5.8 & 64.1 & 69.9 & 67.355 & .1702 & 1.1913 & 1.419 & -.478 & .340 \\
\hline $\begin{array}{l}\text { PACU rm } \\
\text { temp control }\end{array}$ & 39 & 2.2 & 68.0 & 70.2 & 69.333 & .0751 & .4692 & .220 & -.346 & .378 \\
\hline $\begin{array}{l}\text { PACU rm } \\
\text { temp } \\
\text { intervention }\end{array}$ & 38 & 4.6 & 67.0 & 71.6 & 69.837 & .1176 & .7246 & .525 & -1.232 & .383 \\
\hline
\end{tabular}


Table 4. Comparison of Temperature Into \& Out of Pre-op by Group

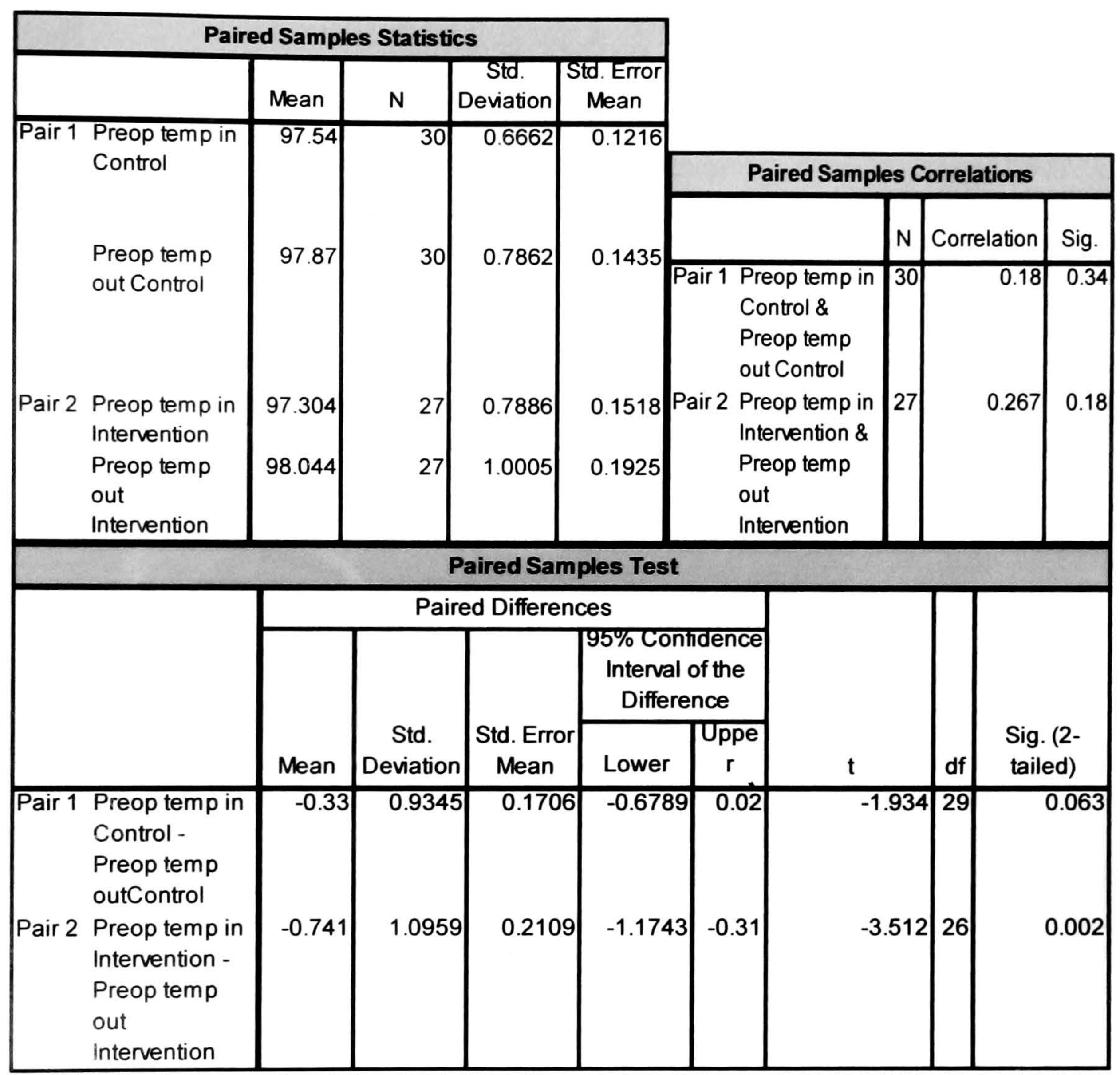


Table 5: Temperatures upon Arrival to Pre-op vs. Arrival to PACU by Group

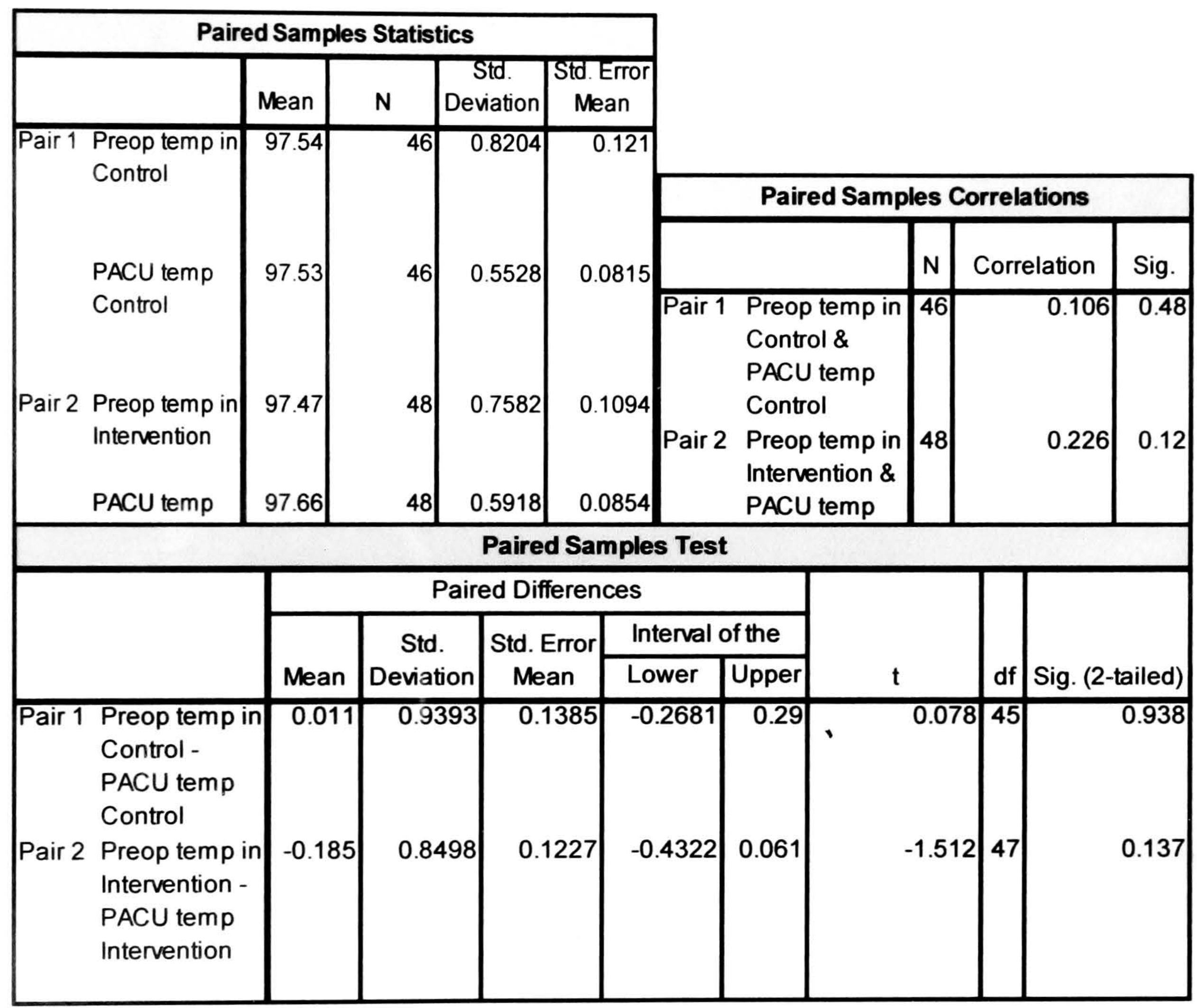


Table 6: Intraoperative Core Temperature between Groups

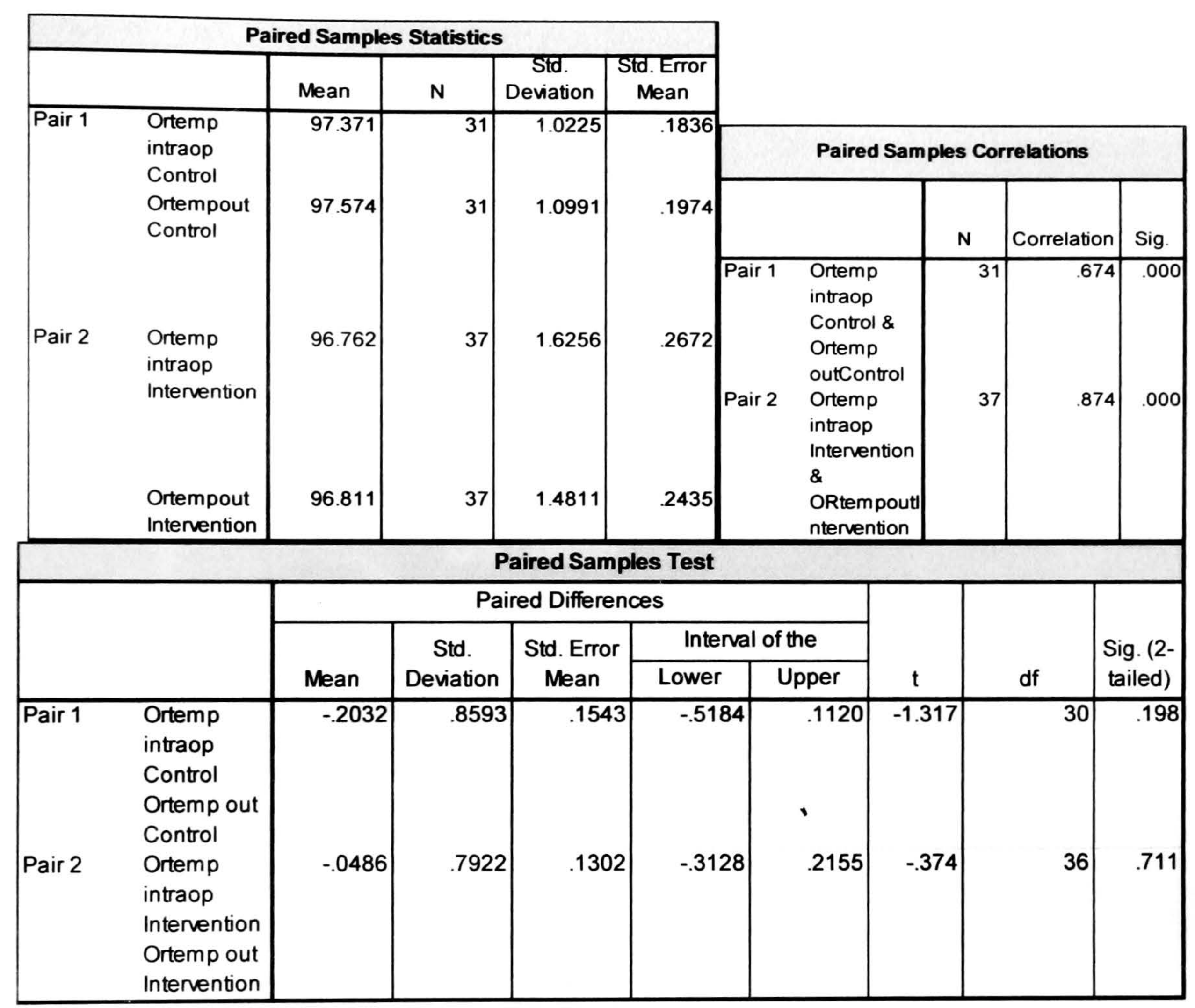


Figure 1. Surgical Procedures in the Control Group

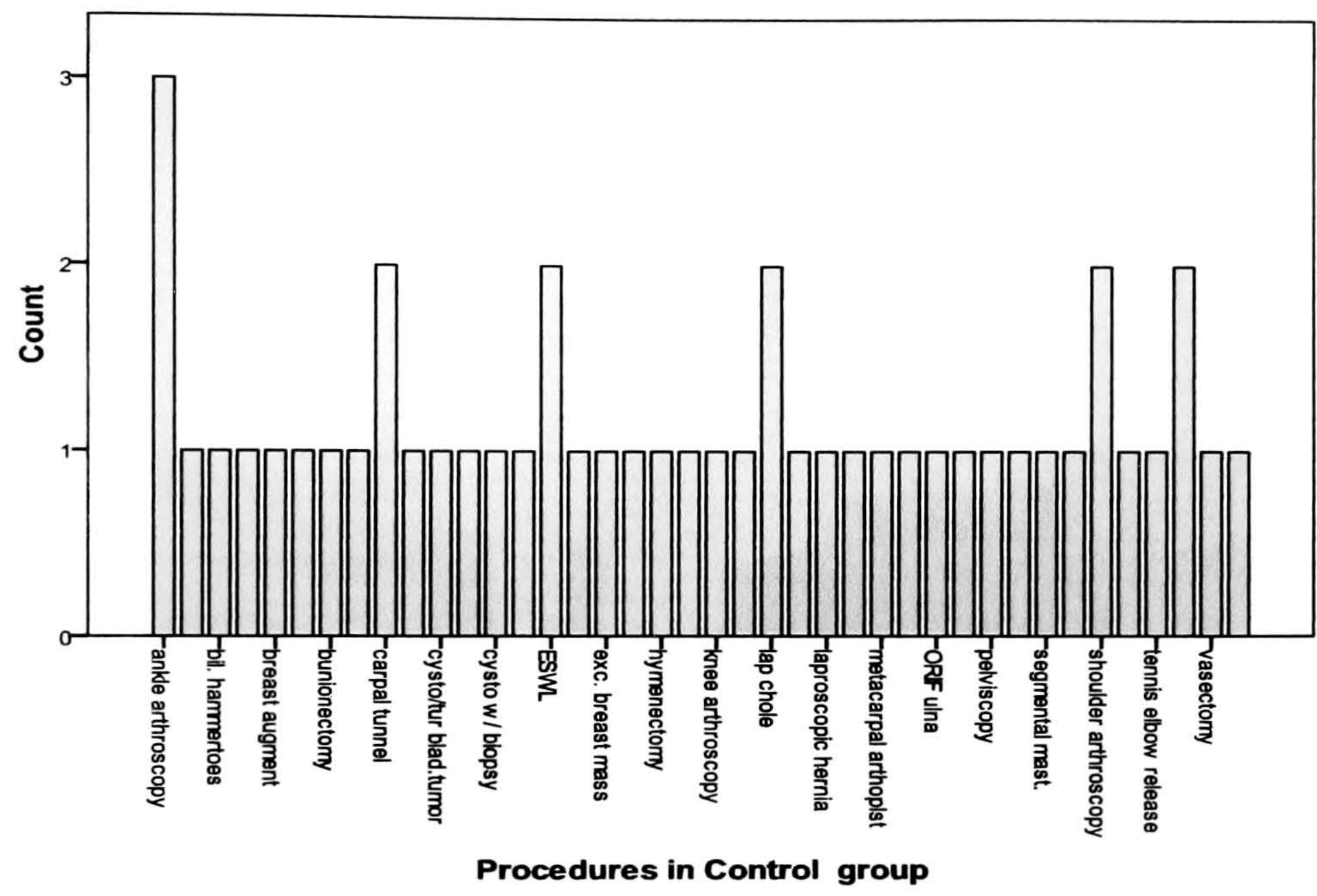


Figure 2: Surgical Procedures in the Intervention Group.

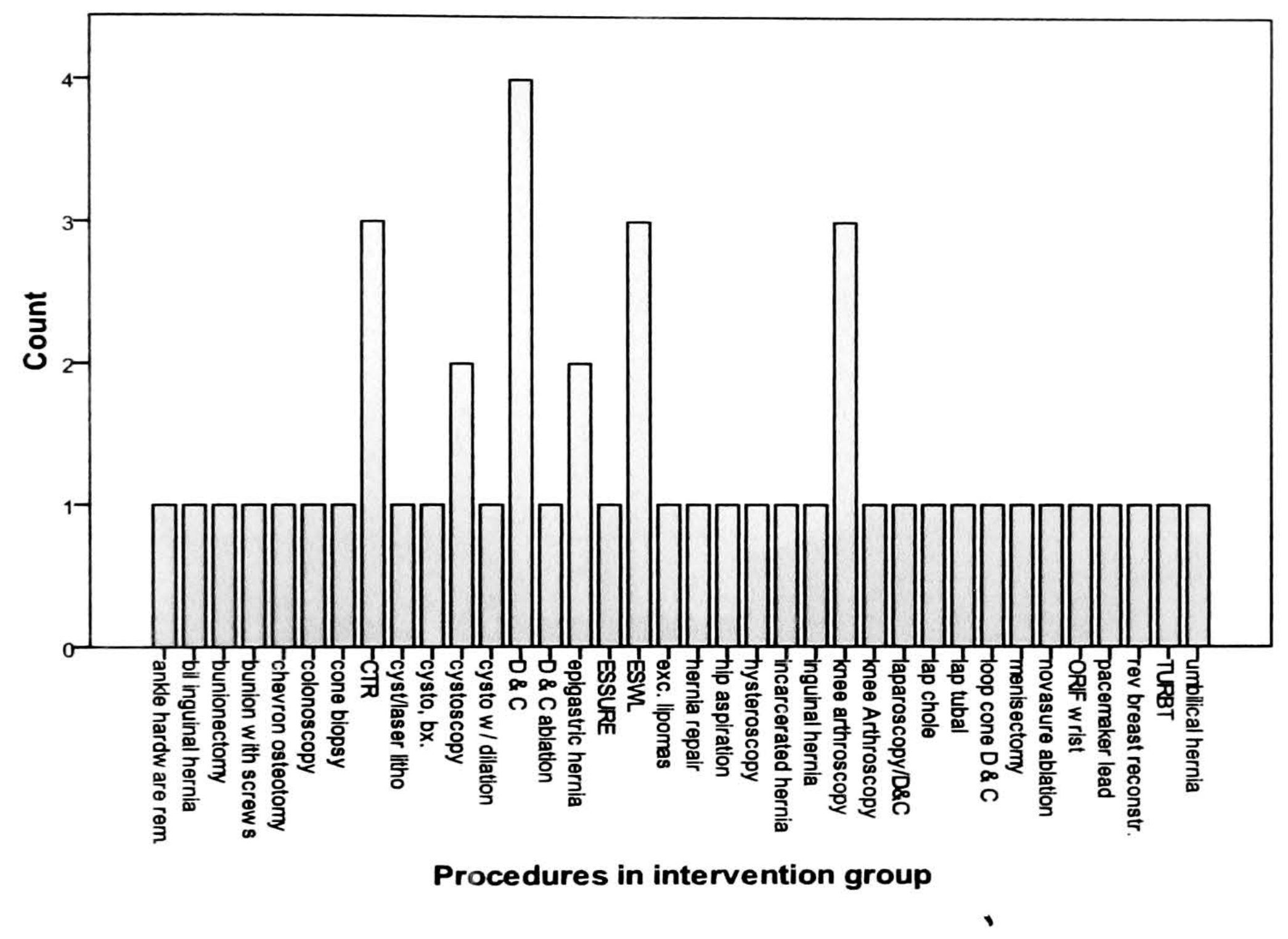

